\title{
Electron Microscopic Anatomy of Motile-phase and Germinating Cells of Dermatophilus congolensis
}

\author{
By J. L. RICHARD, A. E. RITCHIE AND A. C. PIER \\ National Animal Disease Laboratory, Animal Disease and Parasite \\ Research Division, Agricultural Research Service, U.S. Department of \\ Agriculture, Ames, Iowa 50010, U.S.A.
}

(Accepted for publication 4 April 1967)

\begin{abstract}
SUMMARY
'Whole' and autolysed motile-phase cells of Dermatophilus congolensis were examined after negative staining with phosphotungstate. Motile-phase cells and cells in other developmental stages were examined in thin sections. The integument of motile-phase cells was homogeneous and about $30 \mathrm{~m} \mu$ thick and was associated with an outer diffuse capsule-like matrix. Three types of intracytoplasmic organelles and occasionally a large fluid-filled vesicle were present. Flagella varied from a few to more than 50 per cell; their diameter was estimated to be approximately 8-9 $\mathrm{m} \mu$. In autolysed cells, the flagella were seen to be attached to differentiated regions of the cytoplasmic membrane. The peripheral zone of the integument of cells in all developmental stages appeared to undergo sloughing. In 'young hyphal' and 'packet' cells, stratification of the integument was frequently observed. Germinating cells of $D$. congolensis were larger than motile-phase cells and contained characteristic translucent membraneless cytoplasmic inclusions. The general anatomical features of $D$. congolensis, especially of germinating cells, closely resembled those of Streptomyces violaceoruber.
\end{abstract}

\section{INTRODUCTION}

Dermatophilus congolensis is the causative agent of an exudative dermatitis of several animal species including man. Its distinctive developmental cycle with hyphal, motile and germinating phases has been thoroughly described by Thompson (1954) and Roberts (1961). Briefly, this cycle consists of the motile-phase cell becoming non-motile and germinating by formation of a germ tube. The germ tube grows in length and concurrently septations develop in both transverse and longitudinal planes. Through differentiation each hyphal cell becomes transformed into a motile-phase and through dissolution of the hyphal cell wall these motile-phase cells escape. Often the hypha breaks apart into packets of cells and the motile-phase cells escape from these packets. Its biochemical, morphological and colonial characteristics have suggested a taxonomic relationship to the order Actinomycetales (Austwick, 1958; Gordon, 1964). Recently, Gordon \& Edwards (1963) have described its fine structural details, establishing a morphological similarity to Gram-positive bacteria and members of the Actinomycetales; i.e. in thin section the cells exhibit a membraneless nucleoid, thick integument, electron dense cytoplasm and conspicuous (often lamellated) invaginations of the cytoplasmic membrane. They noted that the peripheral substance of the integument of hyphal cells underwent a progressive dissolution before the coccoid 
motile-phase cells were released. The inner zone of the hyphal integument displayed a 'fine network of fibrils enmeshing the coccal forms.' Although their electron micrographs were of high quality, Gordon \& Edwards (1963) were unable to obtain information on the locomotory apparatus of motile-phase cells.

Electron microscopic evidence of flagella-like appendages on coccoid cells of Dermatophilus congolensis was first obtained by Thompson (I954) on shadow-cast specimens. Their presence was confirmed by Edwards using negative-staining (Gordon, 1964). In neither of these studies was the mode of attachment of the flagella to the cell discerned.

Anatomical details reflecting differentiation of motile-phase cells into germinating cells are lacking. The present study was undertaken to obtain a more detailed understanding of the anatomical features of both motile and germinating cells of Dermatophilus congolensis since they have been implicated as responsible for the spread and development of disease (Roberts, 1961).

\section{METHODS}

Dermatophilus congolensis, isolate B (Pier, Richard \& Farrell, 1964) was used. The organism had been maintained for about I year in $10 \%(\mathrm{v} / \mathrm{v})$ serum broth with semimonihly transfers. Colonial growth was established in $72 \mathrm{hr}$ at $37^{\circ}$ on brain-heart infusion agar containing $5 \%(\mathrm{v} / \mathrm{v})$ defibrinated bovine blood. Plates were then incubated at room temperature $\left(23-25^{\circ}\right)$ for periods up to I week. Lowering the incubation temperature enhanced the development of mucoid colonies predominantly populated with organisms in the motile spore stage.

For negative staining, organisms were generally harvested in a minimum volume of distilled water so as to yield a turbid suspension. Portions were then transferred by loop (with thorough mixing) through 4 successive distilled water dilutions in a spottest plate to separate the cells from detritus. Equal volumes of the final suspension of washed cells were then mixed with $2 \%(w / v)$ potassium phosphotungstate (PTA) prepared according to the method of Brenner \& Horne (1959). The organisms were mounted by the 'loop-film' method of Murray (1963) on carbon-coated collodionfilmed grids and examined immediately in a Philips EM 200 electron microscope using double-condenser illumination.

For thin sectioning, organisms were fixed by the method of Kellenberger, Ryter \& Séchaud (1958) and embedded in divinylbenzene (DVB) cross-linked methacrylates (Kushida, 196I). Sections were cut on an LKB Ultrotome with a diamond knife and post-stained with one of several alkaline lead solutions (Karnovsky, 196r ; Millonig, 196I; Reynolds, 1963).

\section{RESULTS}

\section{Negative-stained preparations}

'Whole' cells. Intact Dermatophilus congolensis cells harvested in any stage of growth were generally opaque to the electron beam because of their turgor, dense intracellular contents, and a diffuse capsule-like envelope. Septa, fiagella, and the integument were most readily observed in cells washed free of their capsular substances (PI. I, fig. I).

Occasionally, especially in 7 - to Io-day-old cultures, motile-phase cells were encountered in which intracellular details could be discerned. These cells contained 
large numbers of cytoplasmic inclusions distributed randomly within an otherwise homogeneous matrix (P1. 2, fig. 3). The inclusions represented at least three distinct types: (a) small weakly electron scattering oval bodies measuring less than $25 \mathrm{~m} \mu$; (b) irregularly shaped membranous organelles of moderate electron scattering power and measuring less than $\mathrm{I} 50 \mathrm{~m} \mu$ in maximum diameter, presumably 'plasmalemmasomes' (Gordon \& Edwards, I 963); and (c) smooth-contoured opaque bodies measuring about $100 \mathrm{~m} \mu$. Occasionally, one or more peripherally located fluid-filled vesicles could be recognized by their relative transparency to the electron beam. When their fluid was evaporated by beam energy, reticulation developed within them (P1. 2, fig. 3). Membranous organelles, type $b$ above, did not always appear to be contiguous with the cytoplasmic membrane.

When adequately resolved, the integument appeared homogeneous and measured approximately $30 \mathrm{~m} \mu$ thick (P1. 2, fig. 3). The cytoplasmic membrane could not be recognized in intact cells, perhaps due to close apposition to the cell wall. Flagella generally emerged in tufts from restricted areas of the cell surface (Pl. I. fig. I). The number of flagella per cell was highly variable, ranging from a few to more than 50 . Flagellar diameters, measured in the negative stain, were about 8-9 $\mathrm{m} \mu$. Frequently, cocci possessed flagella while still within the hyphae or packets (Pl. I, fig. I).

Autolysed cells. Motile-phase cells harvested one week or more after obtaining stationary growth phase were collapsed and displayed a wide range of degenerative states (P1. I, fig. 2). The cytoplasm of cells exhibiting minimum autolytic degeneration appeared amorphous or compartmentalized by a complex system of membranes (PI. 2, fig. 4). Both conditions could exist in the same organism. Detachment of the cytoplasmic membrane from the cell wall was common though not extensive. Occasionally, a flagellar basal granule was suspected. Adjacent to the sites of flagellar insertion a large homogeneous centrally located vesicle was frequently noted. Its homogeneity may be due to fluid contents.

More extensively autolysed cells generally displayed a highly contracted cytoplasmic membrane and several smaller membranous sacs within the cell wall (Pl. I, fig. 2; Pl. 2, fig. 5). Flagella were still attached to the cytoplasmic membrane over a limited area but basal granules could not be recognized nor could ultrastructural details of the flagellar attachment site be discerned. It seemed likely, however, that the flagella arose from the cytoplasmic membrane since their insertion through the integument frequently resulted in a characteristic 'shepherd's hook' configuration (P1. 2, figs. 4,5 ). When large numbers of flagella remained with the cell residue they often entwined it like a skein of yarn (Pl. I, fig. 2).

\section{Thin-sectioned preparations}

Cells of Dermatophilus congolensis isolate B as seen in thin sections after embedding in DVB cross-linked methacrylates appeared similar to those of the four strains examined in non-crosslinked methacrylates by Gordon \& Edwards (1963). The cytoplasm of all developmental stages was structurally complex and of generally high contrast. It contained a variety of membranous formations and inclusions and often was separated from the integument by a translucent zone (Pl. 2, fig. 6). Cocci ghosts were also encountered (P1. 4, fig. I2).

The integument was generally of lower contrast than the cytoplasm and its thickness varied from 25 to more than $100 \mathrm{~m} \mu$. This wide range was due principally 
to the angle of sectioning, although the wall of germinating and hyphal cells was usually thicker than that of the motile-phase cells. The integument frequently appeared stratified into zones of different depth and density, most clearly seen in 'packet' cells ( $\mathrm{Pl} .3$, fig. 7) and young unsegmented hyphae (P1. 3, fig. 8). This differentiation was less obvious in free cocci (Pl. 2, fig. 6), septating hyphal cells (Pl. 3, fig. 9) and germinating cells (Pl. 4, figs. IO, II). In 'packet' cells, this stratification frequently appeared as smooth-contoured edges at the septa like a 'bourrelet' configuration (Thompson, 1942) (Pl. 3, fig. 7). The peripheral zone of the integument of most cells was amorphous and appeared to slough as described by Gordon \& Edwards (I963). The presence of this material could account for the encapsulated appearance of motile cocci examined in the negative stain although sloughing was most frequently noted with germinating cells.

Germinating cells were larger than motile-phase cells. In their cytoplasm could usually be seen numerous membraneless translucent inclusions (P1. 4, fig. Io), reminiscent of the storage vacuoles of Streptomyces violaceoruber (Glauert \& Hopwood, 196I). Some germinating cells contained such inclusions in the periphery of their cytoplasm (P1. 4, fig. II). Similar translucent inclusions were less frequently observed in hyphal cells ( $\mathrm{Pl}$. 2, fig. 6). A large chondrioid body was observed in a cell presumed to be in the initial stage of germination (Pl. 4, fig. 12).

The flagellar apparatus could not be seen in thin sections, although numerous variations in fixing and embedding were tried. Only on one occasion was a tuft of fibrils clearly discerned, but no information of their mode of attachment to the cytoplasmic membrane could be obtained (Pl. 4, fig. 13).

\section{DISCUSSION}

Negative-staining of 'whole' or partially autolysed cells served as a useful and complementary technique to thin-sectioning. Anatomical details of the cell including flagella and the number and types of its intracellular inclusions were readily observable in such preparations. Negative stained preparations provided evidence for an attachment of the flagella of Dermatophilus congolensis to the cytoplasmic membrane similar to that found in other Schizomycetes. Cytoplasmic fine structure and stratification of the integument could, however, be revealed only in sectioned specimens.

The cells of Dermatophilus congolensis were marked by an integument of variable thickness (often stratified and subject to sloughing) and a variety of intracellular inclusions. These characteristics further support a taxonomic relationship to the Actinomycetales. The cytoplasmic compartmentalization and numerous inclusions of $D$. congolensis might allow a diversity of functionally interdependent metabolic facilities in keeping with its phylogenetic complexity. Its general anatomical features, especially those of germinating-phase cells, more closely resemble Streptomyces violaceoruber (Glauert \& Hopwood, 196I) than either mycobacteria (Koike \& Takeya, 196I) or Nocardia asteroides (Kawata \& Inoue, 1965). Germinating cells of $D$. congolensis appear to differ from motile-phase cells by being larger and containing numerous translucent membraneless inclusions. The functional significance of these inclusions and the large chondrioid also observed in a germinating cell was not assessed.

The origin of capsular substance associated with most motile-phase cells is unknown. It may represent adhering hyphal integument (Gordon \& Edwards, 1963) or 
it may arise from the coccal wall proper by biosynthetic processes. The presence of 'bourrelet' configurations in the stratified integument suggests that its layers have different physiochemical properties. It would be interesting to know if this inhomogeneity is related to the morphogenesis of the motile-phase cell. Fluid-filled cytoplasmic vesicles in close proximity to the site of flagellar attachment in Dermatophilus congolensis may provide a pool of precursors for flagellar synthesis. A similar consideration has been applied to regions of rarefied cytoplasm observed in the flagellated pole of Spirillum serpens (Murray \& Birch-Andersen, 1963).

Lechevalier \& Holbert (I965) have investigated the flagella of another motile actinomycete, Actinoplanes P 128. From their electron micrographs of shadowed preparations we have estimated the flagellar diameter of this organism as approximately $20 \mathrm{~m} \mu$. For Dermatophilus congolensis the flagellar diameter is 8-9 $\mathrm{m} \mu$, a much smaller figure. Most bacterial flagella are about $12 \mathrm{~m} \mu$ in diameter (Glauert, I962; Rhoades 1965). The 8-9 $\mathrm{m} \mu$ diameter of $D$. congolensis flagella more closely approaches that of the fimbriae (pili) of Escherichia coli (Duguid, 1959; Brinton, 1965) and Klebsiella sp. NCTC 9644 (Thornley \& Horne, 1962), estimated to be about $7 \mathrm{~m} \mu$.

It was our experience, like that of Gordon \& Edwards (1963), that the flagellar apparatus of $D$. congolensis was not revealed in thin sections. A similar circumstance was noted by Lechevalier \& Holbert (1965) with the flagella of Actinoplanes sp. P I28. Information is lacking on the chemical nature of the flagella of both $D$. congolensis and Actinoplanes sp. P I28. Perhaps this information would be of value for developing suitable fixing and embedding procedures for these appendages and their attachment apparatus.

Our observation that cocci often possess flagella before being released from the hyphae could explain the mycelial movement frequently observed in phase contrast microscopy.

The authors wish to thank Mr W. H. Knaack for his skilful technical assistance.

\section{REFERENCES}

Austwick, P. K. C. (1958). Cutaneous streptothricosis, mycotic dermatitis and strawberry foot rot and the genus Dermatophilus Van Saceghem. Vet. Revs. Annotat. 4, 33.

BRENNER, S. \& HoRNe, R. W. (1959). A negative staining method for high resolution electron microscopy of viruses. Biochim. biophys. Acta 34, 103.

Brinton, C. C. (1965). The structure, function, synthesis and genetic control of bacterial pili and a molecular model for DNA and RNA transport in Gram-negative bacteria. Trans. N.Y. Acad. Sci. 27, 1003.

Duguid, J. P. (1959). Fimbriae and adhesive properties in Klebsiella strains. J. gen. Microbiol. 2r, 271.

Glauert, A. M. (1962). The fine structure of bacteria. Br. med. Bull. r8, 245.

Glauert, A. M. \& Hopwood, D. A. (196I). The fine structure of Streptomyces violaceoruber ( $S$. coelicolor). III. The walls of the mycelium and spores. J. biophys. biochem. Cytol. ro, 505.

Gordon, M. A. (1964). The genus Dermatophilus. J. Bact. 88, 509.

Gordon, M. A. \& Edwards, M. R. (1963). Micromorphology of Dermatophilus congolensis. J. Bact. 86, 110 r.

KARNovSKY, M. J. (196I). Simple methods for 'staining with lead' at high pH in electron microscopy J. biophys. biochem. Cytol. $\mathbf{x}, 729$.

KAWATA, T. \& INOUE, T. (1965). Ultrastructure of Nocardia asteroides as revealed by electron microscopy. Jap. J. Microbiol. 9, $10 \mathrm{I}$. 
Kellenberger, E., RYter, A. \& SÉchaud, J. (1958). Electron microscope study of DNA-containing plasms. II. Vegetative and mature phage DNA as compared with normal bacterial nucleoids in different physiological states. J. biophys. biochem. Cytol. 4, $67 \mathrm{I}$.

KoIKE, M. \& TAKEYA, K. (I96I). Fine structures of intracytoplasmic organelles of mycobacteria. J. biophys. biochem. Cytol. $9,597$.

KUSHIDA, H. (1961). A new embedding method for ultrathin sectioning using a methacrylate resin with three dimensional polymer structure. J. Electron Microsc. (Tokyo) ro, 194.

LeCheVAlier, H. \& HolBert, P. (1965). Electron microscopic observation of the sporangial structure of a strain of Actinoplanes. J. Bact. 89, 217.

Millonig, G. (1961). A modified procedure for lead staining of thin sections. J. biophys. biochem. Cytol. II, 736.

Murray, R. G. E. (1963). On the cell wall structure of Spirillum serpens. Can. J. Microbiol. 9, 38 I.

MurRay, R. G. E. \& BirCh-ANDERSEN, A. (1963). Specialized structure in the region of the flagella tuft in Spirillum serpens. Can. J. Microbiol. 9, 393.

Pier, A. C., Richard, J. L. \& FarRell, E. F. (I964). Fluorescent antibody and cultural techniques in cutaneous streptothricosis. Am. J. vet. Res. 25, rol4.

REYNolds, E. S. (1963). The use of lead citrate at high $\mathrm{pH}$ as an electron-opaque stain in electron microscopy. J. Cell Biol. 17, 208.

RHOADES, M. E. (1965). Flagellation as a criterion for classification of bacteria. Bact. Rev. 29, 442.

RoBerTs, D.S. (I96r). The life cycle of Dermatophilus dermatonomus, the causal agent of ovine mycotic dermatitis. Aust. J. exp. Biol. med. Sci. 39, 463.

Thompson, R. E. M. (1954). A species of Rhizobium isolated from strawberry foot-rot in the sheep. J. Path. Bact. 68, 445.

Thompson, W. D'ARCY (1942). On Growth and Form, and ed. Vol. 2, p. 470. Cambridge University Press.

ThoRNLEy, M. J. \& HoRNE, R. W. (1962). Electron microscope observations on the structure of fimbriae with particular reference to Klebsiella strains, by the use of the negative staining technique. J. gen. Microbiol. 28, 51 .

\section{EXPLANATION OF PLATES}

\section{Plate I}

Fig. I. PTA negative stain of portion of ' whole' metamorphosed hypha of Dermatophilus congolensis. Cells contain some intracellular fluid and exhibit septa (S) and flagella (F). Note the two cells at the left in which the protoplast is eccentrically located. $\times 100,000$.

Fig. 2. PTA negative stain of autolysed motile-phase cells from aged colonies. Note persistence of cell wall and flagella $(F)$ associated with one cell. $\times 50,000$.

\section{Plate 2}

Fig. 3. PTA negative stain of intact motile-phase cell with $30 \mathrm{~m} \mu$ cell wall (CW), large reticulated peripheral vacuole (Vac.), and three types of intracellular inclusions (I). Note superposition of images of some inclusions. $\times 125,000$.

Fig. 4. PTA negative stain of partially autolysed motile-phase cells with division of cytoplasm into compartments, large fluid-filled vesicle (Ves.) adjacent to flagellar attachment sites, and detachment of the involuted cytoplasmic membrane (CM) at arrows. Note 'shepherd's crook' configuration of flagella at lower centre. $\times 78,000$.

Fig. 5. PTA negative stain of an extensively autolysed motile-phase cell with collapsed cell wall (CW) and contracted cytoplasmic membrane (CM) with attached flagella. Note diminutive residual inclusions (I). $\times$ 100,000.

Fig. 6. Survey field of thin-sectioned preparation of Dermatophilus congolensis. Note variability of cell-wall thickness, reticular nature of the cytoplasm and variety of inclusions. Cytoplasmic retraction (arrow) was frequently seen in cells of low density. $\times 62,000$.

\section{Plate 3}

Fig. 7. Thin-section of 'packet' cells of Dermatophilus congolensis with cell wall stratification and a 'bourrelet' configuration (B). $\times 73,000$. 
Journal of General Microbiology, Vol. 49, No. 1

Plate 1
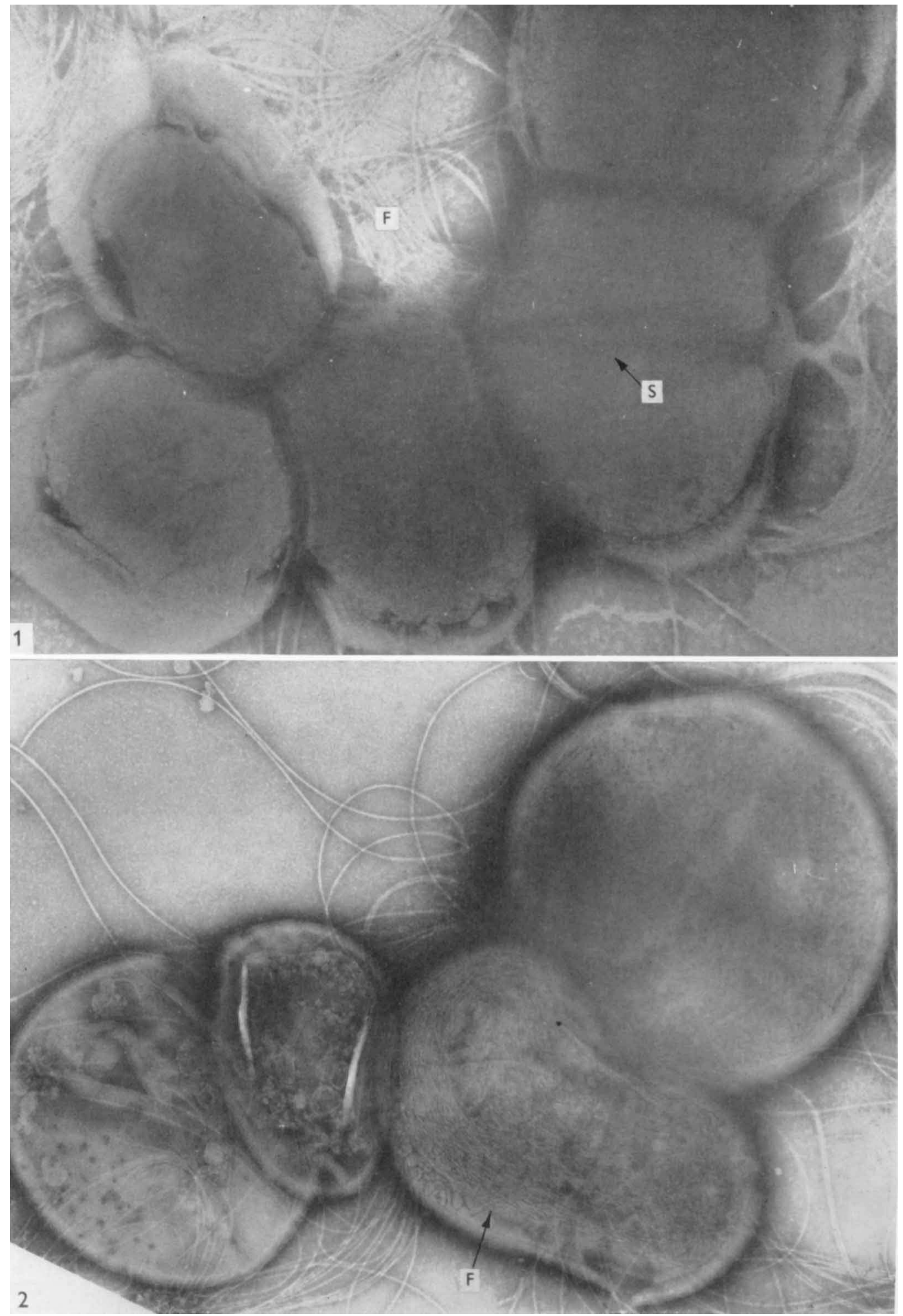

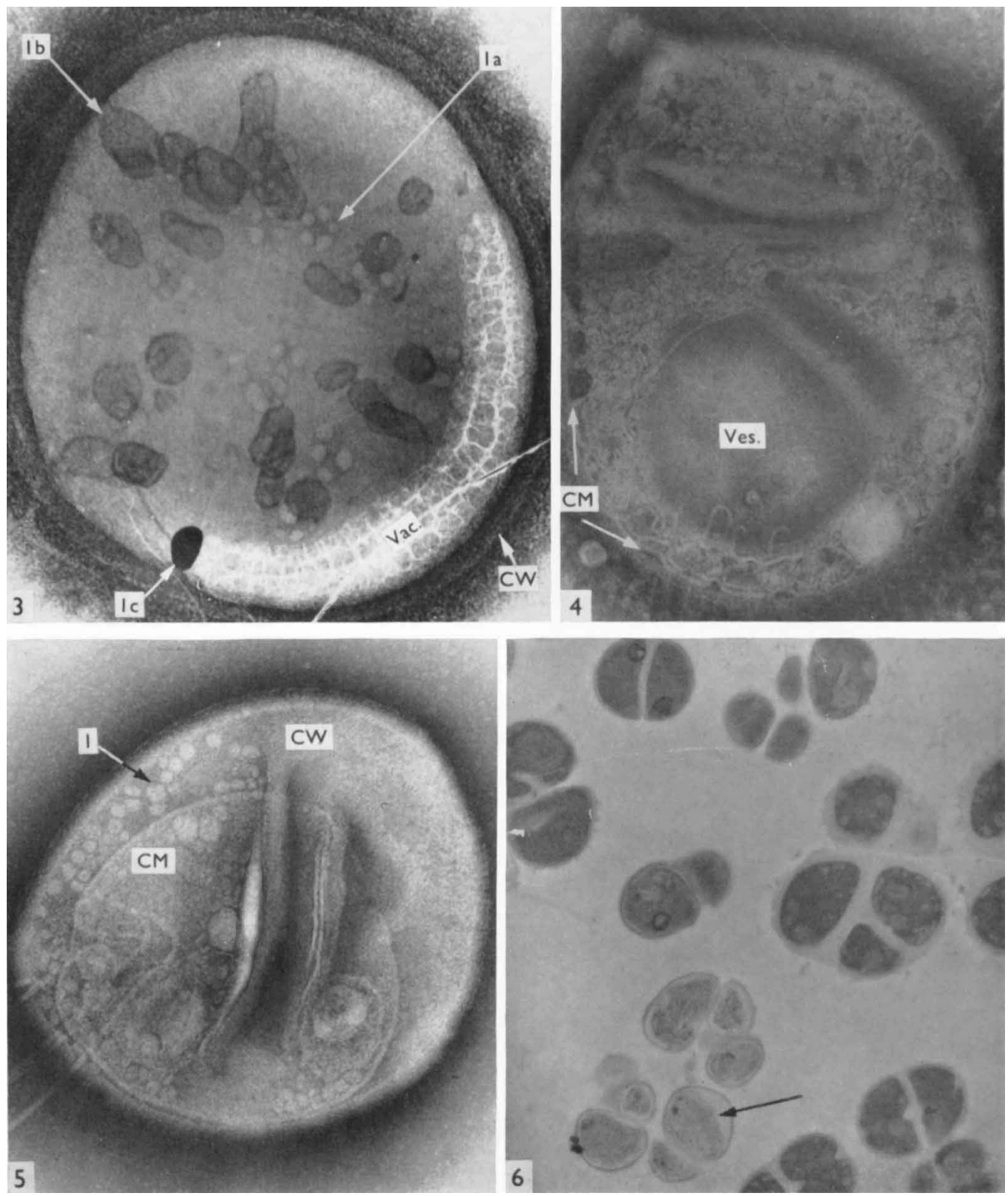

J. L. RICHARD, A. E. RITCHIE AND A. C. PIER 
Journal of General Microbiology, Vol. 49, No. 1

Plate 3
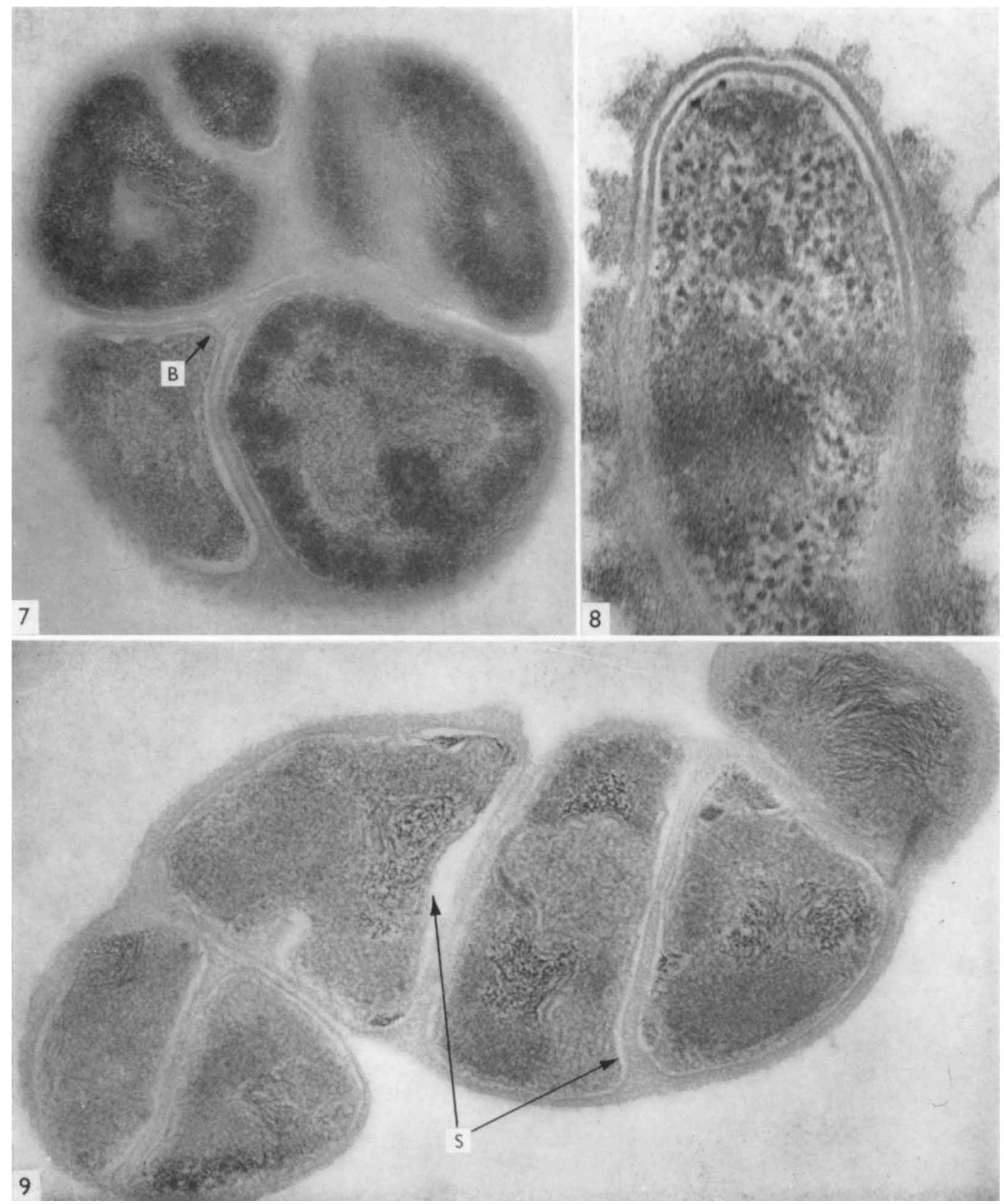
Journal of General Microbiology, Vol. 49, No. 1

Plate 4
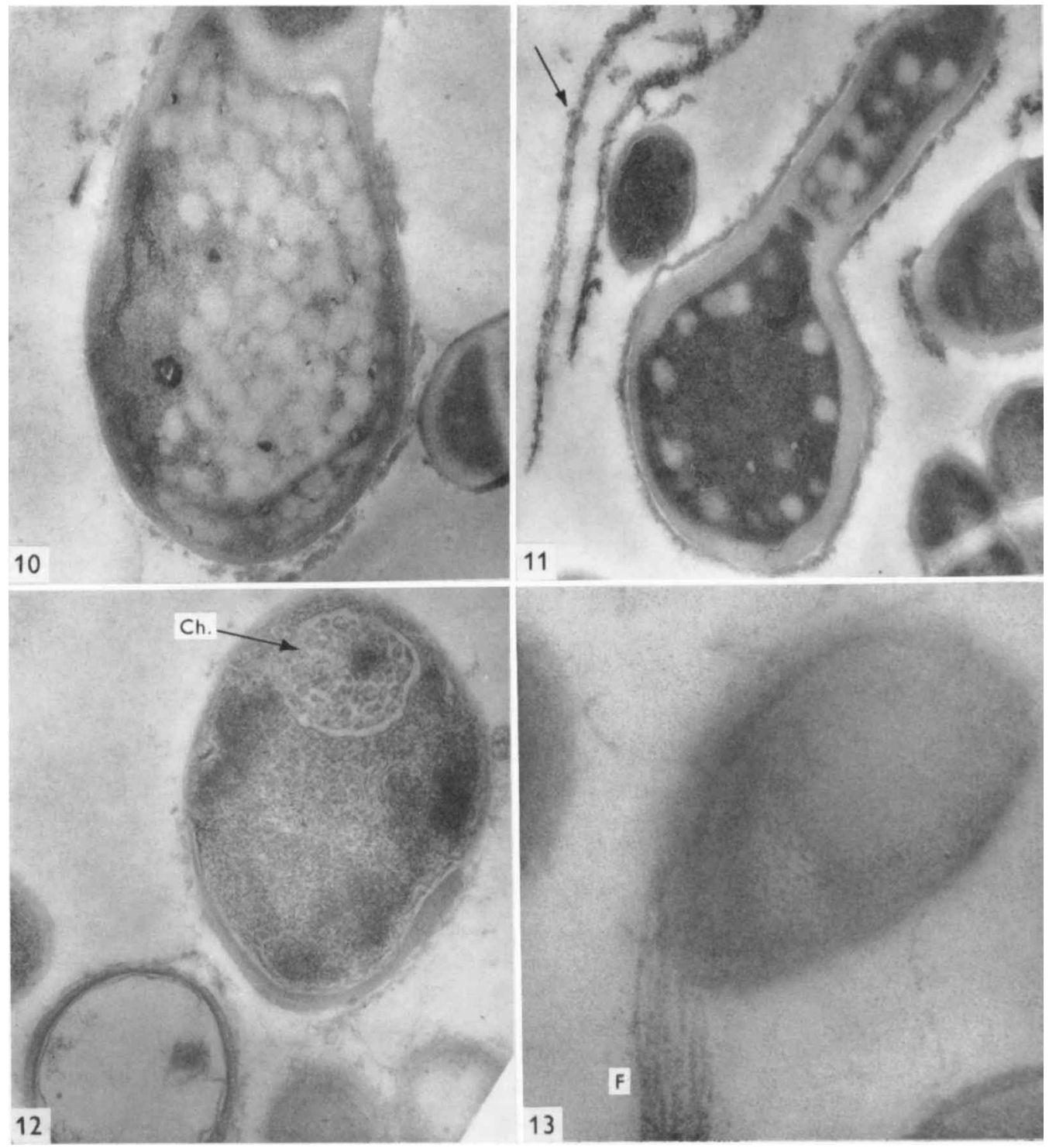

J. L. RICHARD, A. E. RITCHIE AND A. C. PIER 
Fig. 8. Thin-section of terminal portion of young unsegmented hyphal cell with amorphous peripheral cell wall mass and underlying stratification. Note small, dense cytoplasmic granules, presumably ribosomes. $\times 125,000$.

Fig. 9. Thin-section of a portion of a segmenting hypha with complex reticulated cytoplasm. There is little evidence of sloughing of the amorphous cell wall. Note cytoplasmic retraction at the septa (S). $\times 110,000$.

\section{Plate 4}

Fig. 10. Thin-section of germinating spore of Dermatophilus congolensis with numerous membraneless translucent inclusions. Note relative size of germinating cell and hyphal cell at right. $\times 71,000$.

Fig. 11. Thin-section of germinating spore with cell wall sloughing and distribution of translucent cytoplasmic inclusions into the initial hyphal cell. Note cast-off integument material at upper left (arrow). $\times 73,000$.

Fig. 12. Thin-section of germinating spore with large chondrioid (Ch). Note small cell ghost at lower left. $\times 54,000$.

Fig. 13. Thick-section of motile-phase cell with flagellar tuft. $\times 145,000$. 